\title{
The First Two Years of Instituto Estadual do Cérebro Paulo Niemeyer: Initial Results of a Brazilian Public Hospital Dedicated to Neurosurgery
}

\section{Os primeiros dois anos do Instituto Estadual do Cérebro Paulo Niemeyer: resultados iniciais de um hospital público brasileiro dedicado à neurocirurgia}

\author{
Daniel Dutra Cavalcanti ${ }^{1}$ Paulo José Pereira da Mata ${ }^{1}$ Paulo Niemeyer Filho ${ }^{1}$
}

${ }^{1}$ Neurosurgery Department, Instituto Estadual do Cérebro Paulo
Niemeyer, Rio de Janeiro, RJ, Brazil

Arq Bras Neurocir 2018;37:182-189.
Address for correspondence Daniel D. Cavalcanti, MD, Departamento de Neurocirurgia, Instituto Estadual do Cérebro Paulo Niemeyer, Rua do Resende, 156, Rio de Janeiro, RJ, 20230-024, Brazil (e-mail: danieldc.neuro@gmail.com).

\section{Abstract \\ Keywords \\ - history of medicine \\ - neurosurgery \\ - aneurysm \\ - glioma \\ - meningioma}

\section{Resumo}

The dissemination of specialty hospitals throughout the urban centers has revolutionized the full spectrum of care for cardiology, oncology and orthopedics during the last decades. To centralize care, from translational and basic research to clinicians and surgeons, in the same dedicated institution leads to a decrease in complications rates, mortality and possible reductions in the length of hospital stays. Moreover, there has been a significant impact on hospital costs and on the quality of care. The Insituto Estadual do Cérebro Paulo Niemeyer (IECPN, in the Portuguese acronym) was opened in June 2013 in Rio de Janeiro, Brazil. It is the very first high-volume neurosurgical institution in the country. The core foundation of this institution is that the anesthesiologists, intensive care practitioners, nurses, pathologists, radiologists and rehabilitation staffs are trained and live the full management of neurosurgical lesions at the same facility on a daily basis. The present paper seeks to analyze the circumstances in which the institution was planned and opened as well as its complexity, infrastructure and initial results following its first 24 months of operation.

A difusão de unidades hospitalares temáticas nos grandes centros urbanos revolucionou o tratamento de cardiologia, oncologia e ortopedia nas últimas décadas. Concentrar especialistas, desde a pesquisa básica e translacional até clínicos e cirurgiões, em unidades dedicadas a uma especialidade, proporciona menores taxas de complicação, mortalidade e possível redução no tempo de internação, diminuindo os custos de received

September 9, 2015 accepted

November 26, 2015

published online

April 26, 2016
DOI https://doi.org/

$10.1055 / \mathrm{s}-0036-1583315$ ISSN $0103-5355$.
Copyright $\odot 2018$ by Thieme Revinter

Publicações Ltda, Rio de Janeiro, Brazil
License terms

(c) $(1) \$$ 
Palavras-Chave

- história da medicina

- neurocirurgia

- aneurisma

- glioma

- meningioma tratamento e aumentando a prestação de serviço de maior qualidade. O Instituto Estadual do Cérebro Paulo Niemeyer (IECPN) foi inaugurado em junho de 2013, no Rio de Janeiro, como o primeiro hospital nacional de grande porte totalmente dedicado ao manejo neurocirúrgico. O principal fundamento é que equipes de anestesia, enfermagem, intensivismo, patologia, radiologia e reabilitação sejam treinadas e vivenciem o manejo integral das lesões neurocirúrgicas diariamente no mesmo local. Este artigo visa analisar o contexto em que o hospital foi concebido, assim como sua estrutura, complexidade e resultados iniciais nos primeiros 24 meses de operação.

\section{Introduction}

The large number of public hospitals from the three governmental levels in Rio de Janeiro allowed the emergence of several departments of neurosurgery over the years, which, on one hand, expanded the distribution of specialists in most units but, on the other hand, reduced superspecialization in certain subareas, besides restricting the correct allocation of resources in possible centers of reference of the specialty. Most of the units practiced the same general neurosurgery, with a low surgical volume, without becoming a reference in any subarea. Several authors have emphasized the importance and impact of the management of complex pathologies in high-volume centers, especially in large cities. ${ }^{1-6}$

Conceived in 2011 and inaugurated 2 years later, the Instituto Estadual do Cérebro Paulo Niemeyer (IECPN, in the Portuguese acronym), in the city of Rio de Janeiro, is the first thematic public neurosurgery hospital in the country. The objective of the present study is to present the structure, organization, functioning, difficulties and surgical results of the first 24 months of operation of this unit.

\section{Fundamentals}

Current public health policies seek the maximum care of the population at the lowest possible cost. The development of reference centers in several subspecialties in large cities, with a high volume of care, has enabled a better use of the public resources, with lower rates of complication, mortality and a possible reduction in the length of hospital stay. In 1987, Hughes et $\mathrm{al}^{1}$ were pioneers in revealing that a greater hospital volume is directly related to better results.

European and American systematic reviews have also revealed a positive association between the volume of care and the evolution in AIDS, oncologic surgery, coronary angioplasty, cerebral aneurysm and carotid endarterectomy, among other pathologies. Using the hospital admissions database in the United States, Barker et $\mathrm{al}^{4}$ found better mortality, hospitalization, costs, and hospital stay until the definitive discharge in trans-sphenoidal surgery for tumors of the pituitary gland in high-volume hospitals. Likewise, the main guideline for the management of subarachnoid hemorrhage suggests the management of this pathology in centers with a high volume of care (more than 35 subarachnoid hemorrhages annually), evidence-base class I. ${ }^{5}$ Building a hospital unit wholly dedicated to neurosurgery would allow the training and perfection of neurosurgical, neuroanesthetic, neurointensive, and neuroradiological medical support, rehabilitation and nursing staff for mass, repeated assistance, and treatment of certain pathologies.

\section{Infrastructure}

The first part of the facilities was inaugurated in June 2013, consisting of 2 buildings, 1 of assistance and the other administrative. The clinic has four floors, with an outpatient clinic, a surgical center, a hemodynamics center, a three-stage intensive care unit, a two-way magnetic resonance imaging center, a fixed multichannel computer tomograph and a portable tomograph, an epilepsy center, clinical analysis laboratories, pathology and basic research in neurosciences.

The second part of the facilities will provide a teaching and an extension area, with an amphitheater and an auditorium, a radiosurgery unit with a Gamma Knife Perfexion (Elekta Instruments AB, Stockholm, Sweden), as well as another 12-story building that will house hospitalization units (rooms), a major neuropediatric intensive care unit (ICU) and a rehabilitation floor.

\section{Surgical and Hemodynamic Center}

The IECPN has four integrated and automated surgical rooms, all with a surgical microscope, two of them with an endoscopy system. One of the rooms is a hybrid, with intraoperative magnetic resonance imaging (iMRI) of $1.5 \mathrm{~T}$ (-Fig. 1), which, when not in surgical application, is used in three shifts a day for internal and outpatient exams. The hemodynamic service has a fluoroscope dedicated to the investigation and treatment of cerebrovascular diseases in total harmony with the microsurgical team.

\section{Intensive Care Units}

There are three floors of neurological ICUs, and the second floor has 10 beds of immediate short-stay neurosurgical postoperative ICUs. The third floor has 6 beds of neuropediatric ICUs and 11 beds of semi-intensive neurological unit. The fourth floor is the unit of critical patients, mainly those transferred from other units, with subarachnoid hemorrhage. There are 17 beds in this unit, which is equipped with bed computed tomography (CT), transcranial Doppler, bed electroencephalography, monitoring of intracranial 


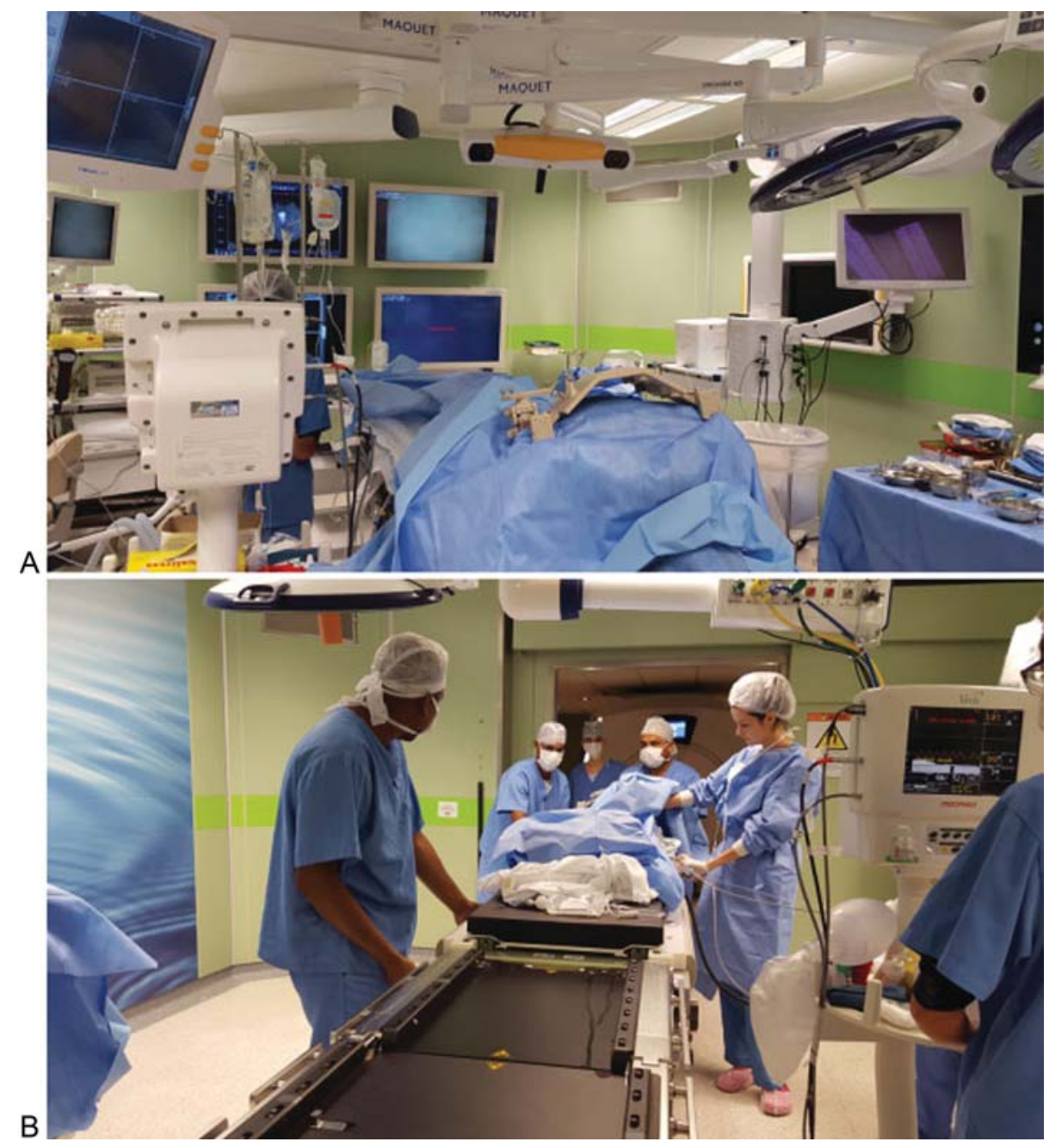

Fig. 1 (A) Surgery in the hybrid room, preparing the patient for intraoperative magnetic resonance imaging, with neuronavigation. The surgical site is covered with new sterile fields, the coils are coupled, as well as the device for immediate neuronal navigation with the new images to be obtained. (B) With the attached room door open, the special magnetic resonance transport stretcher is connected to the surgical table for direct transport of the patient to the apparatus by sliding.

pressure (ICP), partial tissue oxygenation $\left(\mathrm{PTiO}_{2}\right)$, point of care ultrasonography and pulse contour cardiac output (PiCCO) monitoring. Equally important is the presence of active teams of respiratory, motor, and day and night phonoaudiology.

\section{Epilepsy Center}

Within the IECPN, there is a center dedicated to the investigation and support of epilepsy refractory to clinical treatment. Counting with an outpatient clinic and two video-electroencephalography rooms, a multidisciplinary team defines weekly surgical cases. It has become one of the main focuses of attention of the institution for the suppressed demand of these patients in the state of Rio de Janeiro.

\section{Basic Research and Biobank Laboratories}

Two basic research laboratories linked to neurosurgery produce constant material that can translate into our practice. A molecular genetics laboratory for tumors of the central nervous system, coordinated by neuropathologists Prof. Dr. Leila Chimelli and Prof. Dr. Monica Gadelha, and a laboratory of cerebral biomedicine focused on the culture of tumor cells of gliomas and meningiomas, coordinated by Prof. Dr. Vivaldo Moura Neto.

A large biobank stores pieces collected during procedures in the IECPN, with the consent of the patients and their families, and promotes the most diverse researches in these laboratories.

\section{Organization}

\section{Assistance}

As the existence of numerous emergency units in the state with a neurosurgeon on duty meets the demand for the care of traumatic brain injury (TBI) and spinal cord injury (SCI), the focus of care of the IECPN is non-traumatic cranial neurosurgery. Other hospitals in the public network are responsible for the management of large-scale spine surgery, such as Instituto Nacional de Traumatologia e Ortopedia (INTO, in the Portuguese acronym) and Hospital Estadual Adão Pereira Nunes (HEAPN, in the Portuguese acronym). 
The character of the hospital is mainly elective, except for the treatment of subarachnoid hemorrhages. The patients arrive at the unit only through state regulation, either by ambulatory care or by direct transfer from any unit, already with an established surgical diagnosis. Neurosurgery has a primary team responsible for elective surgeries, a daily attendant for intercurrences, and an outpatient team for surgical screening, postoperative evaluation, and clinical follow-up of non-surgical lesions. In total, the surgical team consists of 21 neurosurgeons.

Other thematic outpatient clinics complement the screening and follow-up of the patients in a more comprehensive and specialized manner, including epilepsy rooms, movement disorders, neuroendocrinology, neuro-oncology, pediatric neurosurgery, and neurovascular surgery.

The establishment of a robust department of neuroendocrinology allowed the reference of large-scale patients and the exchange of experiences with two other renowned institutions in the care of the sellar pathologies, the Hospital Universitário Clementino Fraga Filho of Universidade Federal do Rio de Janeiro (UFRJ, in the Portuguese acronym) and the Instituto Estadual de Diabetes e Endocrinologia Luiz Capriglione (IEDE, in the Portuguese acronym). In addition to outpatient screening and preoperative preparation specific to each pathology, patients with hypophyseal adenomas, craniopharyngiomas and other sellar pathologies have immediate postoperative follow-up in the neurosurgery UTI and follow-up with the same team.

\section{Teaching and Research}

The IECPN began to host the 5-year postgraduate course in neurosurgery under the tutelage of the Pontifícia Universidade Católica do Rio de Janeiro (PUC-Rio, in the Portuguese acronym) and the direction of Prof. Dr. Paulo Niemeyer Filho, whose students make their rotation in TBI, SCI and spinal surgery in the HEAPN. At the moment, we have 15 postgraduates, 9 of whom started training at the Santa Casa de Misericórdia in Rio de Janeiro. There are daily morning sessions after the round in the ICUs, in neurovascular, neuroendocrinology, neuro-oncology, pediatric neurosurgery, and epilepsy surgery departments, in addition to the magazine club.

Likewise, the neurosurgery UTI offers a 1-year postgraduate program in neurointensivism, in addition to regular courses of transcranial doppler and bedside electroencephalography. The neuroradiology department also offers the fourth year of residence to general radiologists, and the physiotherapy department also has a specific postgraduate course on preoperative and postoperative management of the neurosurgical patient.

The high volume of care and procedures in the IECPN has allowed each department to lead basic and clinical scientific studies, mainly in the most managed pathologies in the unit -hypophyseal adenomas, gliomas, meningiomas, subarachnoid hemorrhages, cavernomas and epilepsy surgeries.

Key epidemiological data are being prospectively maintained on the REDCap (Research Eletronic Data Capture,

Table 1 Outpatient care volume in the IECPN from June 2013 to July 2015

\begin{tabular}{|l|l|l|l|l|}
\hline Outpatient unit & 2013 & 2014 & 2015 & Total \\
\hline Adult neurosurgery & 474 & 2,269 & 1,549 & 4,292 \\
\hline Pediatric epilepsy & 340 & 1,421 & 899 & 2,660 \\
\hline Adult epilepsy & 312 & 1,386 & 916 & 2,614 \\
\hline Neuroendocrinology & 288 & 1,065 & 775 & 2,128 \\
\hline General medicine & 231 & 486 & 346 & 1,063 \\
\hline Neurovascular & 82 & 584 & 390 & 1,056 \\
\hline Pediatric neurosurgery & 98 & 514 & 403 & 1,015 \\
\hline Anesthesiology & 258 & 450 & 305 & 1,013 \\
\hline Neuro-oncology & 0 & 392 & 469 & 861 \\
\hline Involuntary movement & 131 & 307 & 183 & 621 \\
\hline Psychiatry & 76 & 299 & 199 & 574 \\
\hline Psychology & 61 & 247 & 196 & 504 \\
\hline Neuropsychology & 113 & 210 & 94 & 417 \\
\hline Nutritionist & 43 & 194 & 61 & 298 \\
\hline Pediatrics & 43 & 87 & 46 & 176 \\
\hline Genetics & 26 & 78 & 69 & 173 \\
\hline Metabolism & 27 & 70 & 42 & 128 \\
\hline Phonoaudiology & 29 & 10,118 & 25 & 124 \\
\hline Total & 2,632 & 6,967 & 19,717 \\
\hline
\end{tabular}

Abbreviations: IECPN, Instituto Estadual do Cérebro Paulo Niemeyer. 
Vanderbilt University, Nashville, Tennessee) data platform to facilitate subsequent data collection and analysis. A medical epidemiologist is part of the unit only for the orientation and follow-up of several studies in each department. And finally, a research nurse in neurosurgery completes the academic pillar of the unit and has a strategic function in four points: (1) assisting physicians in collecting data in different studies, (2) feeding the unit's general database, (3) making contact with patients, and (4) assisting in the organization of meetings of research groups.

\section{Initial Results}

A total of 19,717 patients were seen from June 2013 to July 2015 (26 months) in different outpatient clinics-- Table 1 discriminates care by sector. The overall volume of monthly care increased 18\% between 2014 (monthly average of 843.17) and 2015 (monthly average of 995.29).

A total of 2,272 patients were operated on in the IECPN from August 2013 to July 2015 (24 months), 229 of which were by endovascular intervention. Considering the 2,043 procedures performed at the surgical center, the monthly average was $87.52 \pm 12.70$ (60-115) surgeries per month (excluding the $1 \mathrm{st}$ month of operations of the operating rooms, when only 1 room was open). There was an evolving progression in the monthly average, with $78.75 \pm 16.44$ (6094) surgeries per month in 2013 and $96.4 \pm 13.90$ (70-115) in 2015. The daily average of surgeries during working days in this range was $4.0(1-8)$.

-Fig. 2 shows the division of procedures by macroareas. There is a clear predominance in the management of neoplastic lesions, with $48.6 \%$ of the total. Vascular neurosurgery represented the 2 nd major area undergoing surgical movement, with $20.4 \%$, while the sum of the procedures for hydrocephalus management represented the 3rd position (13.1\%). We will now describe the specific volume of the main lesions covered in the IECPN by macroarea.

\section{Central Nervous System and Skull Tumor Surgery}

The mean monthly tumor surgeries were $36.0 \pm 6.7$ (22-46), excluding the 1 st month of operations. Using the 2007 World Health Organization (WHO) classification, gliomas were the main group of tumors managed in the IECN, representing $29.0 \%$ of the total number of tumors (-Table 2 ). Glioblastoma multiforme alone accounted for $59.9 \%$ of the 227 astrocytic tumors, $43.2 \%$ of the total gliomas and $12.5 \%$ of the total number of tumors in this series.

Pituitary adenoma represented $23.1 \%$ of the operated tumors; - Table 3 shows the distribution of these lesions. The 249 meningeal tumors constituted $22.9 \%$ of all neoplasms - - Table 4 reveals the distribution, while - Fig. 3 stratifies the meningiomas by location. Of the 236 meningiomas, $85.6 \%$ were benign WHO I, $10.6 \%$ were atypical (WHO II) and 3.8\% were anaplastic (WHO III).

Seventy-six brain metastases were operated on, accounting for $7.0 \%$ of all neoplasms. The highest incidence was of pulmonary focus metastases (43.4\%), followed by those with no primary focus (19.7\%), and breast metastases (14.5\%). Tumors of the cranial and peripheral nerves represented the

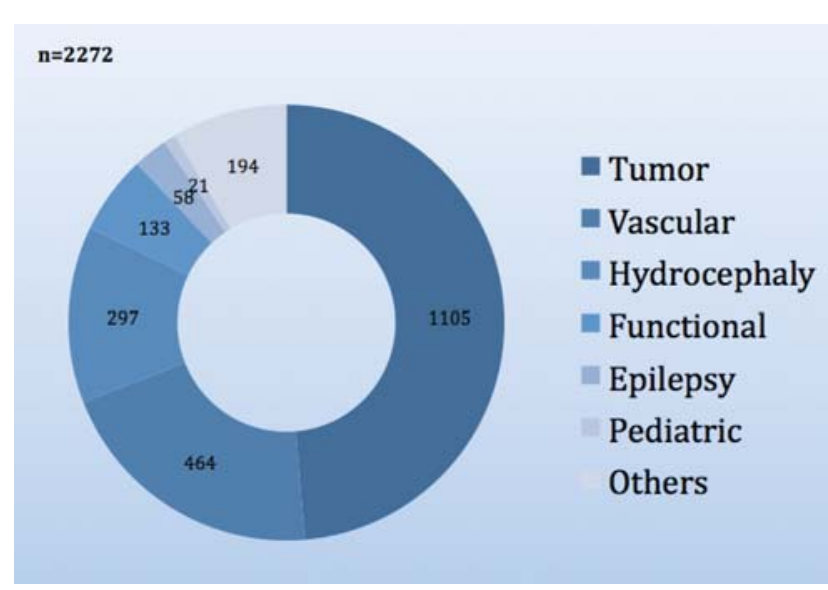

Fig. 2 In the first 24 months of operation, 2,272 procedures were performed in the IECPN. Of this total, 229 endovascularly. There was a clear predominance of surgery of tumors of the central nervous system and skull. The "Other" category included decompressive craniectomies, cranioplasties, intracranial hematoma surgeries, abscesses and empyemas, Chiari malformations, and wound revisions. Abbreviations: IECPN, Instituto Estadual do Cérebro Paulo Niemeyer.

5th position among the neoplasms, with 75 schwannomas and 1 intradural Neurofibroma of the C1 root. Of these, 69 were vestibular (90.8\%); 2 were trigeminal; 2 were of the hypoglossal nerve; 1 was of the nerves of the jugular foramen; and 1 was of the facial nerve. The other histopathological diagnoses will be detailed in another article.

Table 2 Distribution of the gliomas operated on at the IECPN from August 2013 to July 2015

\begin{tabular}{|l|l|}
\hline Gliomas & Total \\
\hline Astrocytic tumor & 227 \\
\hline Glioblastoma multiforme & 136 \\
\hline Pilocytic astrocytoma & 36 \\
\hline Astrocytoma grade II & 24 \\
\hline Astrocytoma grade III & 21 \\
\hline Gliosarcoma & 9 \\
\hline Subependymal astrocytoma & 1 \\
\hline Oligodendroglial tumors & 42 \\
\hline Oligodendroglioma II & 21 \\
\hline Oligodendroglioma III & 21 \\
\hline Neuronal and glioneuronal mixed tumors & 31 \\
\hline Malignant glioneuronal & 13 \\
\hline Ganglioglioma I & 12 \\
\hline Ganglioglioma III & 4 \\
\hline Papillary glioneuronal tumors & 1 \\
\hline Ganglioglioma II & 1 \\
\hline Ependymal tumors & 15 \\
\hline Ependymoma grade III & 12 \\
\hline Ependymoma grade II & 3 \\
\hline Total & 315 \\
\hline
\end{tabular}

Abbreviations: IECPN, Instituto Estadual do Cérebro Paulo Niemeyer. 
Table 3 Distribution of hypophyseal adenomas operated in the IECPN from August 2013 to July 2015

\begin{tabular}{|l|l|}
\hline Adenomas & Total \\
\hline Nonfunctioning & 135 \\
\hline GH secretors & 60 \\
\hline ACTH secretors & 38 \\
\hline Prolactinomas & 13 \\
\hline Thyrotropinomas & 5 \\
\hline Total & 251 \\
\hline
\end{tabular}

Abbreviations: ACTH, adrenocorticotropic hormone; $\mathrm{GH}$, growth hormone; IECPN, Instituto Estadual do Cérebro Paulo Niemeyer.

Table 4 Distribution of meningeal tumors operated at the IECPN from August 2013 to July 2015

\begin{tabular}{|l|l|}
\hline Meningeal tumor & Total \\
\hline Meningioma & 236 \\
\hline Hemangioblastoma & 6 \\
\hline Hemangioma & 2 \\
\hline Hemangiopericytoma & 2 \\
\hline Osteoma & 1 \\
\hline Solitary fibrous tumor & 2 \\
\hline Total & 249 \\
\hline
\end{tabular}

Abbreviations: IECPN, Instituto Estadual do Cérebro Paulo Niemeyer.

\section{Vascular Neurosurgery}

In total, 464 microsurgical and endovascular procedures were performed. Treatment of intracranial aneurysms accounted for $80.6 \%$ of the vascular procedures. There were 203 microsurgeries and 171 embolizations for the treatment of aneurysms. Subarachnoid hemorrhage occurred in 50.5\% of the patients. Exactly $50 \%$ of the patients submitted to clipping had middle cerebral artery aneurysms (MCAs), while $27.3 \%$ had posterior communicating artery aneurysms, and $18.7 \%$ had anterior communicating artery aneurysms.



Fig. 3 Topographic distribution of the 236 meningiomas operated on in the first 2 years of the IECPN. Meningiomas of convexity were the most prevalent in the unit, representing almost $30 \%$ of the total. Skull base meningiomas accounted for $55.1 \%$ of the total. Abbreviations: IECPN, Instituto Estadual do Cérebro Paulo Niemeyer.
Among the embolized aneurysms, the distribution was less disparate, with prevalence of the anterior communicating artery (19.1\%).

Twenty-one cavernous malformations were operated on during the period covered in the present study. Twelve of them were supratentorial ( 5 frontal, 2 in the caudate, 2 temporal, 1 in the rotation of the Cingulate gyrus, 1 in the radiated crown, and 1 parietal); 7 in the brainstem; and 2 cerebellar.

Nine arteriovenous malformations were addressed, seven of which with hybrid treatment-embolization associated with microsurgery. Three were frontal, three occipital, two parietal, and one cerebellar. As for the Spetzler-Martin classification, four were grade III; four were grade II; and one was grade $\mathrm{I}^{7}$

Six cerebral bypasses were made, all extra and intracranial. Of these, five were from the superficial temporal artery to the middle cerebral artery (branches M3 or M4); and one was from a high-flow, external carotid artery to M3, using a radial artery graft.

\section{Functional Neurosurgery}

Although it represented 5.9\% ( $n=133)$ of the surgical movement, the mass treatment of movement disorders became one of the great differentials of the institute. The surgical management of Parkinson disease prevailed, accounting for $51.9 \%$ of surgical care; trigeminal neuralgia accounted for 24.1\%; dystonia, $10.5 \%$; facial spasm, $4.5 \%$; essential tremor, $3.0 \%$; and glossopharyngeal neuralgia, $2.3 \%$ and revision of DBS system $3.7 \%$.

\section{Pediatric Neurosurgery}

With only six beds, the pediatric neurosurgical movement was significantly lower. A total of 264 procedures were performed on children and adolescents. We have verified that 122 (46.2\%) of these procedures were tumor resections; 41 (15.5\%) were procedures for hydrocephalus management; 20 vascular surgeries ( 9 aneurysms, 4 arteriovenous malformations [AVMs], 2 trunk cavernomas, 2 supratentorial cavernomas, 1 low-flow bypass for Moya-Moya disease, 1 dural arteriovenous fistula and 1 Galene malformation); 9 craniosynostosis; 7 tethered spinal cord; 1 Chiari malformation; and 1 encephalocele; among others general procedures.

\section{Epilepsy Surgery}

The surgical treatment of temporal lobe epilepsy accounted for most of the surgeries in this group, with $36.2 \%$ of the 58 procedures. Twelve were selective amygdalohippocampectomies, and nine included anterior lobectomy. The vagus nerve stimulator implant corresponded to $20.7 \%$ of the total; callosotomies, $12.1 \%$; and hemispherectomies, $5.2 \%$. There was also a deep cerebral electrode implant in one case.

\section{Discussion}

The last decades saw the superconcentration of selected specialties in their own units to provide integral treatment in a single environment or institution as well as to promote excellence in teaching and research, generating national 
epidemiology. The Instituto Nacional de Cardiologia (National Institute of Cardiology; INC, in the Portuguese acronym), Instituto Nacional do Câncer (National Institute of Cancer; INCA, in the Portuguese acronym) and the INTO, in Rio de Janeiro, as well as the Instituto do Câncer do Estado de São Paulo (Cancer Institute of the State of São Paulo; ICESP, in the Portuguese acronym) and Instituto do Coração (Heart Institute; InCor, in the Portuguese acronym), in São Paulo, promote their specialties through mass assistance, training of specialists and the generation of specific public policies. ${ }^{8,9}$

The fragmentation of neurosurgical departments in several Brazilian states, both within and outside universities, in a context of restriction of investments within the Unified Health System (SUS, in the Portuguese acronym), contradicts the worldwide tendency to concentrate high-complexity procedures in high-volume centers. ${ }^{1-6,8,9}$ There is extensive evidence in the literature that morbidity and mortality are lower when patients are treated at high-volume reference centers by superspecialized physicians. ${ }^{4,6}$ Still, in 2002, Birkmeyer et al ${ }^{10}$ showed a significant reduction of operative mortality in complex abdominal and cardiovascular procedures when operated in high-volume versus low-volume institutions in the USA. A decade later, analyzing the results of 3.2 million patients undergoing oncological or cardiovascular surgeries, Finks et al ${ }^{11}$ ratified that management in high-volume centers reduces surgical mortality in various pathologies. But these authors also reinforce the need for safe surgery initiatives, constant improvement in quality, outcome measures and constant prognosis (all of which are more easily performed in a specialized unit). In short-term results, morbidity and mortality are consistently lower in trans-sphenoidal surgery for sellar lesions in high-volume hospitals, with lower rates of hospitalization and even a lower cost trend. ${ }^{4}$ Similar impacts were revealed in the microsurgical management of trigeminal neuralgia and ventriculoperitoneal shunting in children in centers with a high volume of treatment. ${ }^{12,13}$

High-volume neurosurgery centers may be located within universities (The department of neurosurgery at the Karolinska Institutet, Sweden, and the neurosurgery service of Universidade de São Paulo [USP, in the Portuguese acronym] Medical School), linked to private institutions but operating in independent buildings (Barrow Neurological Institute, Phoenix, AZ, USA; Burdenko Institute, Moscow, Russia). ${ }^{14-16}$ As an example, the Karolinska Institutet had already performed 3,000 neurosurgeries annually with four surgical rooms, Gamma Knife and hemodynamics, two decades ago. ${ }^{15}$ The Barrow Neurological Institute has demonstrated how a high volume produces better results in pathologies once rare in other centers, such as cavernous malformation of the brainstem, encouraging teams from all departments to produce knowledge in genetics, molecular biology and radiology. ${ }^{17,18}$

The IECPN was conceived in January 2011 as a model of rapid resolution, both for ambulatory neurosurgical patients and for transfers from another center, based on a high volume of approach to cranial neurosurgical pathologies. Inaugurated in June 2013, it was named after Paulo
Niemeyer, one of the founders of the Sociedade Brasileira de Neurocirurgia (Brazilian Society of Neurosurgery-1957), who introduced the surgical microscope in the specialty in Brazil, and author of the description of the amygdalohippocampectomy (1958). ${ }^{19}$

By concentrating specialists such as neuroanesthetists, neuroendocrinologists, specialists in neurointensive care, neuropathologists, neuro-oncologists and neuroradiologists, as well as physiotherapists, speech therapists, psychologists, nutritionists and nurses deeply specialized in neurosurgery, all working in a high volume of cases, using specific protocols, a more agile and complete treatment to each patientis provided. The identification of complications inherent to each disease or procedure, and the management of these, is significantly faster. In parallel, an environment conducive to basic and multidisciplinary clinical research in neurosurgery will result in a greater knowledge development and in a specific national literature, will highlight the most incidental pathologies to guide society, and will allow the promotion of public agencies with data for aid in the development of specific public policies, together with other major national institutions.

Tumor microsurgery represented $48.6 \%$ of the surgical movement in the first 24 months of operations of the IEPCN. Gliomas accounted for $29 \%$ of all tumors; pituitary adenomas, 23.1\%; and meningeal tumors, $22.9 \%$. Hybrid vascular neurosurgery represented $20.4 \%$ of the total movement, and it is worth highlighting the perfect balance between microsurgery and endovascular therapy, either because of the number of clusters versus embolizations, or because of the 9 open rotated AVMs operated, 8 were submitted to preoperative embolization.

The greater development of functional and epilepsy surgeries in the state of Rio de Janeiro, although they occupy the fourth and fifth positions in volume, respectively, may represent one of the greatest impacts of the institute's installation. Of a total of 133 patients operated by the functional neurosurgery group, 30 received deep brain stimulators $-53.3 \%$ for Parkinson disease. The multidisciplinary group of the epilepsy center, meanwhile, performed 280 monthly visits to screen 58 patients operated on in the period covered by the present study (except for lesionectomies with neoplasic outcome).

\section{Limitations}

The evaluation of other external specialists, mainly urologists, hematologists, vascular and plastic surgeons, is not always as ideally ready as in a university hospital, but in no case has it compromised the multidisciplinary care of the patient. A general surgery recall team responds promptly in cases of emergency thoracoabdominal procedures.

\section{Conclusion}

Following the revolutions caused by the centralization of the integral care of cardiology, oncology, orthopedics and traumatology in dedicated institutions, with a high volume in recent decades, Brazilian neurosurgery presents its first step in this model. The implementation of dedicated institutes 
allows the government to prioritize investments in the same unit for maximum use of the entire technological apparatus and increase productivity. In addition, it creates a great reference for patients, generating a volume that translates into greater team experience, knowledge generation, and better training for future generations.

The dissemination of the initial results of the IECPN, the impact on local health and the future cost-effectiveness analysis of the procedures can guide the development of other units of the same size in other metropolitan regions with a high demographic concentration.

\section{References}

1 Hughes RG, Hunt SS, Luft HS. Effects of surgeon volume and hospital volume on quality of care in hospitals. Med Care 1987;25 (06):489-503

2 Luft HS, Hunt SS, Maerki SC. The volume-outcome relationship: practice-makes-perfect or selective-referral patterns? Health Serv Res 1987;22(02):157-182

3 Begg CB, Cramer LD, Hoskins WJ, Brennan MF. Impact of hospital volume on operative mortality for major cancer surgery. JAMA 1998;280(20):1747-1751

4 Barker FG II, Klibanski A, Swearingen B. Transsphenoidal surgery for pituitary tumors in the United States, 1996-2000: mortality, morbidity, and the effects of hospital and surgeon volume. J Clin Endocrinol Metab 2003;88(10):4709-4719

5 Connolly ES Jr, Rabinstein AA, Carhuapoma JR, et al; American Heart Association Stroke Council; Council on Cardiovascular Radiology and Intervention; Council on Cardiovascular Nursing; Council on Cardiovascular Surgery and Anesthesia; Council on Clinical Cardiology. Guidelines for the management of aneurysmal subarachnoid hemorrhage: a guideline for healthcare professionals from the American Heart Association/american Stroke Association. Stroke 2012;43(06):1711-1737

6 Amato L, Colais P, Davoli M, et al. [Volume and health outcomes: evidence from systematic reviews and from evaluation of Italian hospital data]. Epidemiol Prev 2013; 37(2-3, Suppl (Suppl 2):1-100
7 Spetzler RF, Martin NA. A proposed grading system for arteriovenous malformations. J Neurosurg 1986;65(04):476-483

8 Linhares E, Gonçalves R, Valadão M, et al. Gastrointestinal stromal tumor: analysis of 146 cases of the center of reference of the National Cancer Institute-INCA. Rev Col Bras Cir 2011;38(06):398-406

9 Lisboa LA, Moreira LF, Mejia OV, et al. [Evolution of cardiovascular surgery at the Instituto do Coração: analysis of 71,305 surgeries]. Arq Bras Cardiol 2010;94(02):162-168, 174-181, 164-171

10 Birkmeyer JD, Siewers AE, Finlayson EV, et al. Hospital volume and surgical mortality in the United States. N Engl J Med 2002;346 (15):1128-1137

11 Finks JF, Osborne NH, Birkmeyer JD. Trends in hospital volume and operative mortality for high-risk surgery. N Engl J Med 2011;364 (22):2128-2137

12 Kalkanis SN, Eskandar EN, Carter BS, Barker FG II. Microvascular decompression surgery in the United States, 1996 to 2000: mortality rates, morbidity rates, and the effects of hospital and surgeon volumes. Neurosurgery 2003;52(06):1251-1261, discussion 1261-1262

13 Smith ER, Butler WE, Barker FG II. In-hospital mortality rates after ventriculoperitoneal shunt procedures in the United States, 1998 to 2000: relation to hospital and surgeon volume of care. J Neurosurg 2004; 100(2, Suppl Pediatrics)90-97

14 Konovalov AN, Yartsev VV, Likhterman LB. The Burdenko Neurosurgery Institute: past, present, future. Neurosurgery 1997;40 (01):178-185

15 Lindquist C, Kihlström L. Department of Neurosurgery, Karolinska Institute: 60 years. Neurosurgery 1996;39(05):1016-1021

16 Lochhead RA, Abla AA, Mitha AP, et al. A history of the Barrow Neurological Institute. World Neurosurg 2010;74(01):71-80

17 Abla AA, Lekovic GP, Turner JD, de Oliveira JG, Porter R, Spetzler RF. Advances in the treatment and outcome of brainstem cavernous malformation surgery: a single-center case series of 300 surgically treated patients. Neurosurgery 2011;68(02):403-414, discussion 414-415

18 Cavalcanti DD, Kalani MY, Martirosyan NL, Eales J, Spetzler RF, Preul MC. Cerebral cavernous malformations: from genes to proteins to disease. J Neurosurg 2012;116(01):122-132

19 Cavalcanti DD, Guasti JA, Preul MC. Neurological and architectural sinuosities: the Niemeyer brothers. Neurosurgery 2010;67(05): 1167-1179 